\title{
Peningkatan Konektivitas Service VPLS Redundant Path Dengan Rapid Spanning Tree Protocol
}

\author{
Fikri Iqromuddin ${ }^{1}$, Novi Dian Nathasia ${ }^{2}$, Iskandar Fitri ${ }^{3}$ \\ ${ }^{1}$ fikri1892@gmail.com, ${ }^{2}$ novidian@civitas.unas.ac.id, ${ }^{3}$ tektel2001@yahoo.com \\ Fakultas Teknologi Komunikasi dan Informatika, Universitas Nasional
}

\begin{abstract}
Virtual Private LAN Service is already very popular among the enterprise industry which is a point to point network or multipoint to multipoint I2VPN service, VPLS provides transparent bridge between customers connected to geographically dispersed locations delivered via MPLS backbone by utilizing features such as MPLS Fast reroute and traffic engineering. Redundant paths can be applied to the VPLS service on the access side and backbone to maintain link performance that aims to minimize down time during network fails on the VPLS service. In this research, the implementation of redundant path using $R S T P$ to prevent forwarding loop switching network in VPLS service to protect end-to-end data traffic with VPLS meshpseudowire and spoke-pesudowire with RSTP is the most optimal result compared to STP and build reliable network System with high performance for use in modern industry.
\end{abstract}

Intisari-Virtual Private LAN Service sudah sangat popular di kalangan industri enterprise yang merupakan jaringan point to point atau multipoint to multipoint l2VPN service, VPLS menyediakan transparan bridge antara customer yang terkoneksi dengan lokasi terpisah secara geografis yang di deliver melalui MPLS backbone dengan memanfaatkan feature seperti MPLS fast reroute dan traffic engineering. Redundant path dapat di terapkan pada service VPLS di sisi akses maupun backbone untuk menjaga performa link yang bertujuan untuk meminimalisir down time saat network fail pada service VPLS. Dalam penelitian ini di implementasikan redundant path menggunakan RSTP guna mencegah forwarding loop switching network pada service $V P L S$ agar terlindungnya traffic data secara end to end dengan hasil VPLS mesh-pseudowire dan spoke-pesudowire dengan RSTP merupakan hasil yang paling optimal dibandingkan dengan STP dan terbentuk reliable network system dengan high performance untuk di gunakan pada modern industri.

Kata Kunci - MPLS, Pseudowire, RSTP, Redundant, VPLS

\section{PENDAHULUAN}

Seiring dengan meningkatnya kebutuhan industri enterprise, maka dibutuhkan teknologi canggih untuk memenuhi segala kebutuhan tersebut, tantangan bagi penyedia layanan adalah menigkatkan performa network dan inovatif untuk memenuhi kebutuhan kritis ini. Industri enterprise membutuhkan koneksi antar site dengan kriteria high bandwith, plug and play dan simple sevice peering. Dalam rangka improve availability, perlu di perhatikan failure yang terjadi pada network yang mengakibatkan menurunnya network availability. Dengan segala kebutuhan ini layanan
VPLS merupakan salah satu solusi tersebut. Virtual Private LAN Service (VPLS) mengkoneksikan point to point atau multipoint to multipoint Ethernet bridging via IP/MPLS backbone, semua customer yang terhubung dalam VPLS yang sama menjadi segment $L A N$ yang sama terlepas dari lokasi yang berbeda. VPLS memanfaatkan segala keuntungan dari MPLS infrastruktur, seperti traffic engineering pada transport tunnel, tunnel resilient feature, convergensi backbone untuk multiple service, namun VPLS service perlu di proteksi secara end to end untuk menghindari segala macam network fail.

\section{PENELITIAN TERKAIT}

Pada penelitian sebelu mnya yaitu penerapan spanning tree pada VPLS yang di bagi menjadi dua yaitu customer asociated dan provider asociated pada flat desain VPLS [1] dengan hasil spanning tree dapat transmited broadcast frames melalui VPLS network tanpa mengirim broadcast storm dan dapat mengurangi waktu konvergensi pada segment network provider maupun customer. Pada VPLS flat desain, fungsi n(n - 1)/2 mesh-pseudowire harus di terapkan pada VPLS dimana $\mathrm{n}$ adalah member $P E$ router yang berpartisipasi pada service VPLS. VPLS flat desain menggunakan mesh-pseudowire untuk koneksi antar $P E$, pengurangan jumlah mesh-pseudowire dapat mengakibatkan loss koneksi dengan masalah data plane maupun control plane untuk skala network yang luas. Dimana akan banyaknya packet untuk di replicate dan pengelolaan pseudowire pada sevice VPLS.

VPLS interopebility dengan CE bridge di bagi dua kategori yaitu mandatory dan optional [2], kategori mandatory yaitu memastikan pengopreasian VPLS yang tepat dengan $C E$ bridge dalam kasus ketika attachment circuit mengunakan $V L A N$ maka $P E$ perlu menyesuaikan dengan perangkat $C E$ seperti penyesuaian protocol spanning tree. Sedangkan optional yaitu penyediaan tambahan operational dalam rangka improvement dan efficiency VPLS seperti redundancy dalam kasus melindungi primary PE fails agar reroute ke backup PE.

Peneliti sebelumnya juga sudah membahas tentang threerings redundancy industri Ethernet menggunakan RSTP [3], dengan hasil terbentuk network system yang benar-benar handal dan real time performance dengan sedikit packet loss.

A wal mulanya, IETF membagi dua standar pengembangan VPLS network dengan signaling Border Gateway Protocl (BGP) [4] dan signaling Label Distribution Protocol (LDP) [5] berdasarkan arsitektur ini perlu di terapkan mekanis me failure handling dalam VPLS untuk meningkatkan avilability. Pada kedua standar VPLS ini di jelaskan keuntungan pada mekanis me VPLS yang ada dari sisi kemudahan dan efisiensi dalam meyediakan service VPLS pada [6]. Bedasarkan control 
plane skalabilitas, tantangan besar dengan LDP VPLS adalah pengelolaan full mesh targeted LDP session dimana dalam BGP VPLS dapat mengatasi masalah ini dengan route reflection [7].

Pada penelitian ini akan di buat desain VPLS redundant path dengan LDP signaling pada pseudowire dan redundant di sisi akses sebagai kategori optional dari VPLS interopebility. Bagaimanapun, redundancy path dapat menyebabkan forwarding loop yang akan menjadi masalah serius seperti broadcast storm, multiple frame transmission dan ketidakstabilan database MAC (Media Acces Control) address. Untuk mengatasi masalah ini Rapid Spanning Tree Protocol (RSTP) dapat di gunakan untuk mengontrol data traffic dan pemanfaatan failure handling pada switching segment untuk meningkatkan availability network. Tujuan dari penulisan penelitian ini diantaranya adalah sebagaiberikut [8] :

1. Membuktikan tidak terjadinya forwarding loop pada network VPLS dengan topologiyang di buat.

2. Meminimalisir down time ketika terjadi network fail pada jaringan VPLS redundant path di sisi akses maupun backbone network RSTP.

\section{METODE PENELITIAN}

Dalam penelitian ini akan di implementasikan redundant path pada service VPLS dengan Alcatel lucent sebagai perangkat network backbone dan cisco sebagai perangkat akses dengan variasi Rapid Per-Vlan Spanning Tree Protocol yang di simu lasikan dalam GNS3. Implementasi multi vendor ini menjadi penting karena survey pada real network beroperasi dengan multi vendor.

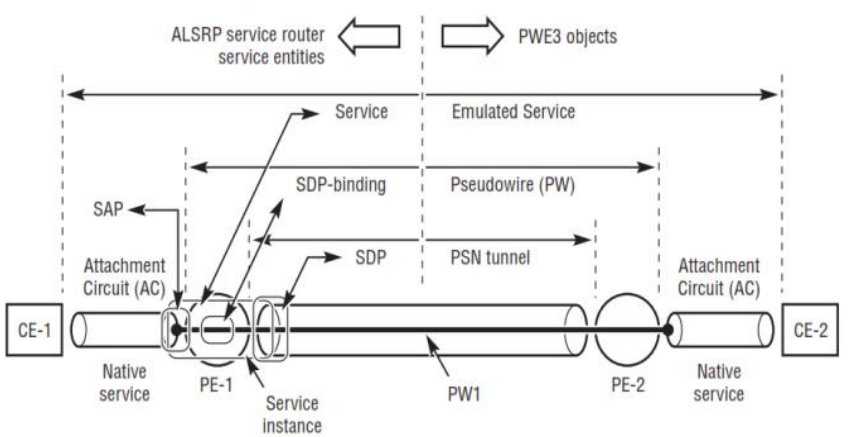

Gambar 1, Perbandingan Service Model ALSRP Dengan PWE3 Model

Gambar $1 \mathrm{di}$ atas merupakan referensi model $P W E 3$ (Pseudo Wire Emulation Edge-to-Edge) dengan ALSRP (Alcatel-Lucent Service Router Portfolio) [7], model di atas merupakan keperluan dalam penyediaan pseudowire emulation untuk Ethernet yang menunjukan point to point service. Arsitektur ini di terapkan juga pada multipoint service seperti VPLS.
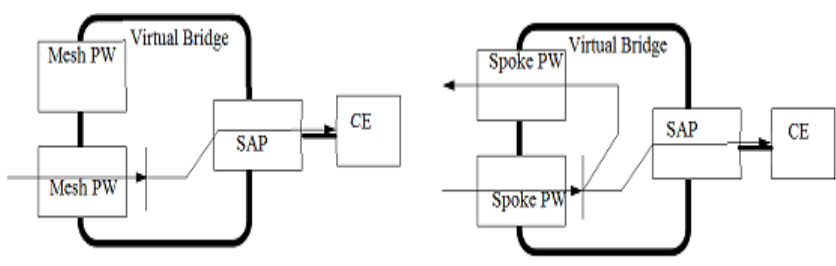

Gambar 2, Ilustrasi Perbandingan Forwarding Mesh PW dan Spoke PW
ALSRP mengidentifikasi service dengan service-ID, model service menggunakan logical service entity untuk me mbangun service dengan atribut Service Acces Point (SAP), Service Distribution Path (SDP), SDP-binding. ALSRP membagi 2 tipe pseudowire $(P W)$ yaitu spoke dan mesh.

Gambar 2 merupakan Ilustrasi forwarding packet yang di terima dari pseudowire, mesh-pseudowire pada VPLS selalu loop-free ini dikarenakan mesh-pseudowire mematuhi aturan split-horizon ketika forwarding traffic antar $P E$ yang bunyinya "do not relay traffic among mesh-psedowire" yang bermaksud split-horizon melarang pengiriman traffic dari mesh-pseudowire ke sesama mesh-pseudowire dalam service yang sama.

Selain mesh-psedowire, VPLS dapat menggunakan spokepseudowire sebagai solusi dari skalabilitas VPLS untuk koneksi antar $P E$, namun tipe pseudowire ini memungkinkan terjadinya masalah seperti forwarding loop dalam VPLS karena spoke-pseudowire tidak mematuhi aturan split-horizon. Spoke-pseudowire membolehkan pertukaran traffic ke semua forwarding entity dalam service (mesh-pseudowire, spokepseudowire dan SAP). Maka pada redundant spokepseudowire perlu di terapkan STP untuk menghidari forwarding loop dan dapat juga di gunakan sebagai alternate forwarding.

\section{A. Pertimbangan VPLS STP dengan Redundant Path}

STP dalam VPLS di bedakan menjadi 2 istilah yaitu transparan mode dan participant mode. Dalam transparan mode, STP dalam status shutdown pada VPLS, VPLS flood $B P D U$ yang di terima dari node lainnya namun tidak memproses $B P D U$ tersebut. VPLS memperlakukan STP $B P D U$ yang di terima sama seperti data frame lainnya yaitu replicate BPDU danflood ke semua pseudowire (mesh, spoke) sama halnya dengan BUM (broadcast, unicast, multicast) traffic.

Dalam participant mode, STP protocol enable dalam $V P L S$ dan memproses BPDU packet yang di terima dari node lain untuk memastikan tidak terdapat forwarding loop. VPLS mengkonsumsi dan menghasilkan BPDU untuk menentukan root bridge, root port dan designated port.

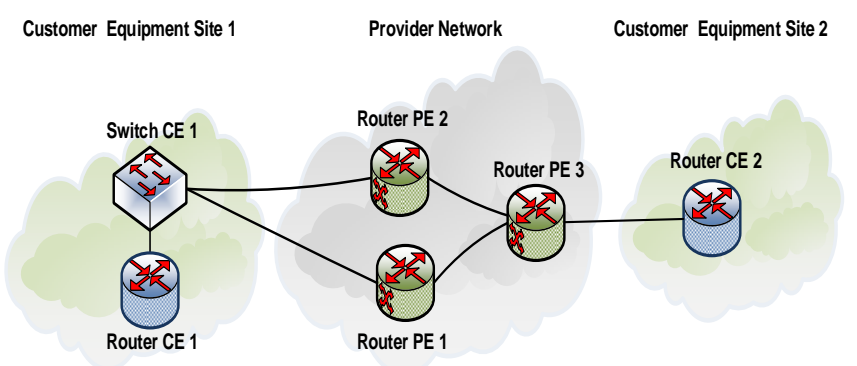

Gambar 3, Ilustrasi Service VPLS Redundant Path

Terlihat dari gambar merupakan jaringan VPLS point to point, tiga router $P E$ sebagai jaringan backbone, switch sebagai jaringan akses, redundant di terapkan di sisi akses dengan variasi Rapid-PVST+ dan juga backbone dengan redundant pseudowire. Dalam kategori mandatory, mode Rapid-PVST+ memungkinkan untuk setiap VLAN yang ada pada switch maupun node $P E$ memiliki private spanning tree masing-masing dimana penukaran $B P D U$ hanya berlangsung 
pada port grup vlan dan service VPLS yang di tetapkan. STP menggunakan variasi $B P D U$ dengan protocol multicast grup $M A C$ address dari $01-80-2 c-x x-x x-x x$, beberapa propriety $S T P$ implementasinya menggunakan $M A C$ address lain untuk $B P D U$ destinasi MAC address. Dalam participan mode perlu di perhatikan $S T P$ kompatibel dengan perangkat node lain yang terkoneksi dengan VPLS. VPLS ALSRP kompetibel dengan beberapa variasi $S T P$ seperti $R S T P$, Comp-dot $1 w, S T P$ dan Cisco PVST+. Pentingnya memperhatikan STP kompetibel karena ketika terjadi perubahan topologi yang di sebabkan link fail STP tidak akan beroprasi. STP antar node mungkin akan memilih forwarding dan blocking port yang berbeda.

\section{B. Tahap Konfigurasi Desain}

Konfigurasi desain VPLS Redundant Path dengan penerapan RSTP ini di simulasikan pada simulator GNS3.

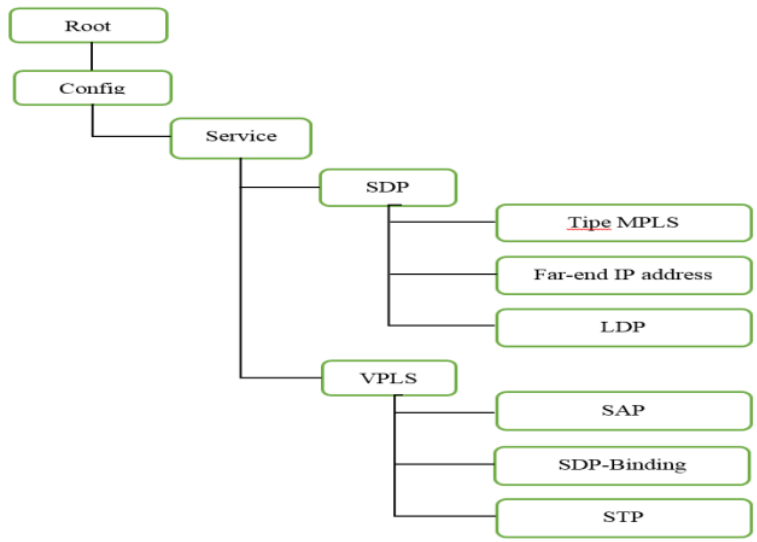

Gambar 4, Step Konfigurasi Service Pada PE

SDP merupakan logical service direct untuk mengkoneksikan antar node $P E$ mele wati service tunnel. SDP pada setiap $P E$ menggunakan MPLS Transport tunnel untuk transport traffic service VPLS pada network backbone antar $P E$. Behubung SDP bersifat unidireksional maka PE local dan remote harus dibuat $S D P$ agar terbentuk koneksi bidireksional. $S D P$ ini menggunakan $L D P$ untuk mendistribusikan informasi router-id untuk mencapai router $P E$ la in dengan label binding. Pada service VPLS yang di simulasikan ini menggunakan LDP-signaled untuk me mbawa traffic mele wati MPLS tunnel. Targeted-LDP (TLDP) di gunakan untuk memberikan sinyal status pseudowire.

Konfigurasi Service VPLS pada setiap me mber $P E$ perlu di masukan logical SAP dan SDP-Binding, dalam simu lasi ini di terapkan SAP encapsulasi dot $1 q$ untuk forwarding packet ke customer site dan spoke atau mesh SDP-binding/pseudowire untuk forwarding traffic melewati network backbone.

Pada gambar 5 terlihat step konfigurasi pada switch, dengan topologi redundant link ini data traffic di kontrol oleh $R S T P$ pada switch yang saling bertukar BPDU dengan VPLS untuk memastikan hanya satu link active forwarding.

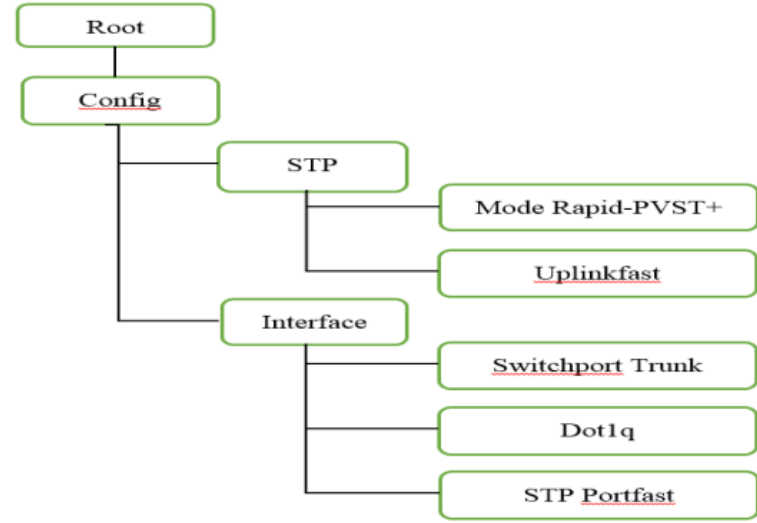

Gambar 5, Step Konfigurasi Pada Switch CE

$B P D U$ in i berisikan root-id, root path cost, bridge identifier (bridge-id) dan port identifier (port-id). Ip address di setting point to point antar router $C E$. Sebagai perspektif user/customer segment layer 3 hanya ada pada end user atau segment customer sendiri dan di sisi VPLS/backbone provider hanya menyediakan segment layer 2 untuk transport data frame.

\section{HASIL DAN PEMBAHASAN}

Berdasarkan desain VPLS network yang di simulasikan dengan GNS3 di lakukan pengujian availability network dengan parameter packet send, packet receive, packet loss dan durasi down time network secara real time, hal ini untuk membuktikan peningkatan konektifitas service VPLS redundant path dengan $R S T P$ sebagai failure handling pada network.

$\begin{array}{lll}\text { Customer Equipment Site } 1 & \text { Provider Network } & \text { Customer Equipment Site } 2\end{array}$

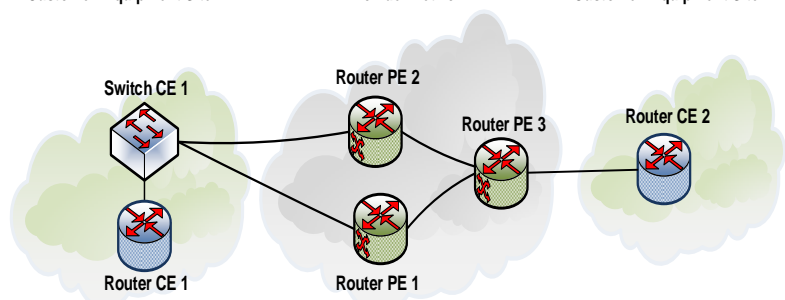

Gambar 6, Desain Redundant Path Pada Service VPLS

Konfigurasi tipe pseudowire pada VPLS di terapkan mesh dan spoke untuk membandingkan kualitas network dan perbandingan mekanis me pencegahan loop STP dan RSTP untuk failure handling, pada spoke-pseudowire diharuskan pemilihan transparan dan participant mode pada setiap VPLS karena perancangan yang tidak tepat akan mengakibatkan forwarding loop pada VPLS.

\section{A. Hasil Pengujian Redundant Spoke Pseudowire VPLS}

Hasil pengujian ini di dapat dengan cara ICMP ping real time dan mematikan link berdasarkan kemungkinan network fail.

Pengamatan ini di uji dengan pengiriman 20 packet pada network, hasil pengujian ini menggunakan VPLS redundant spoke-pseudwire dengan membandingkan penerapan STP dan RSTP. Spoke-pseudowire melakukan pertukaran traffic ke semua forwarding entity dalam service (mesh-pseudowire, 
spoke-pseudowire dan SAP) dan membentuk multi bridge network sehingga dapat membentuk loop forwarding.

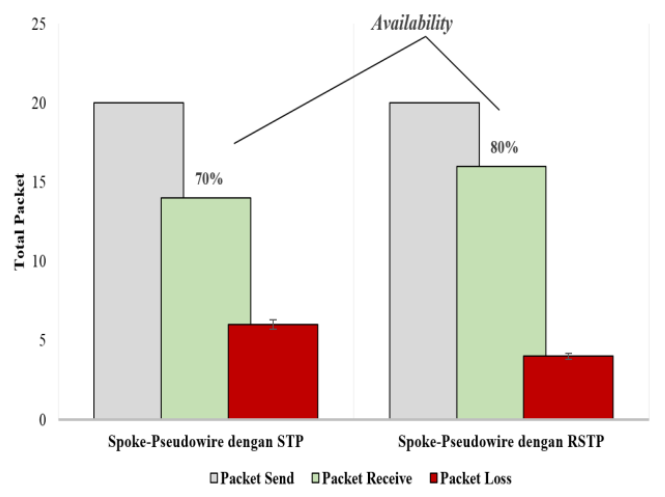

Gambar 7, Grafik Pengamatan Availability VPLS Spoke Pseudowire

Dalam desain ini mekanis me pencegahan loop berhasil membuat single spoke-pseudowire dalam status backup/discard, backup spoke-pseudowire berubah menjadi forwarding hanya ketika active spoke-pesudowire down. Dengan ini redundant pseudowire akan beroperasi dengan baik dan tidak membentuk forwarding loop dan di dapat hasil availablility dengan RSTP $80 \%$ dimana hasil ini dapat mempercepat waktu konvergensi network di bandingkan dengan STP yang di dapat hasil $70 \%$.

\section{B. Hasil Pengujian Redundant Mesh Pseudowire VPLS}

Metode pengujian ini sama dengan redundant spoke pseudowire VPLS sebelu mnya, yaitu ICMP ping real time dan mematikan link berdasarkan kemungkinan network fail.

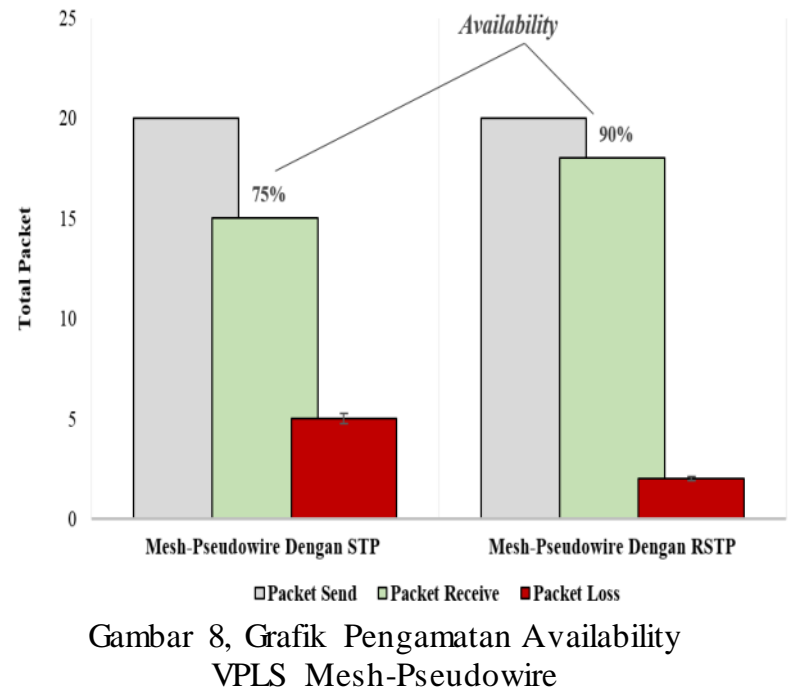

Hasil pengujian ini menggunakan VPLS redundant meshpseudowire, mesh-pseudowire pada VPLS selalu loop-free dalam forwarding traffic antar node dikarenakan aturan splithorizon maka mekanisme pencegahan loop ini hanya beroperasi pada interface akses VPLS kearah customer. Maka di dapat hasil mesh-psseudowire membentuk single bridge pada network dan tidak membuat forwarding loop, berdasarkan pengamatan konvergensi RSTP di dapat availability network $90 \%$ dimana ini mengindikasikan performa lebih tinggi di bandingkan STP yang hanya mendapat $75 \%$.

\section{Durasi Down Time Network}

Dari pengujian yang di lakukan sebelumnya di dapat durasi down time pada network secara real time.

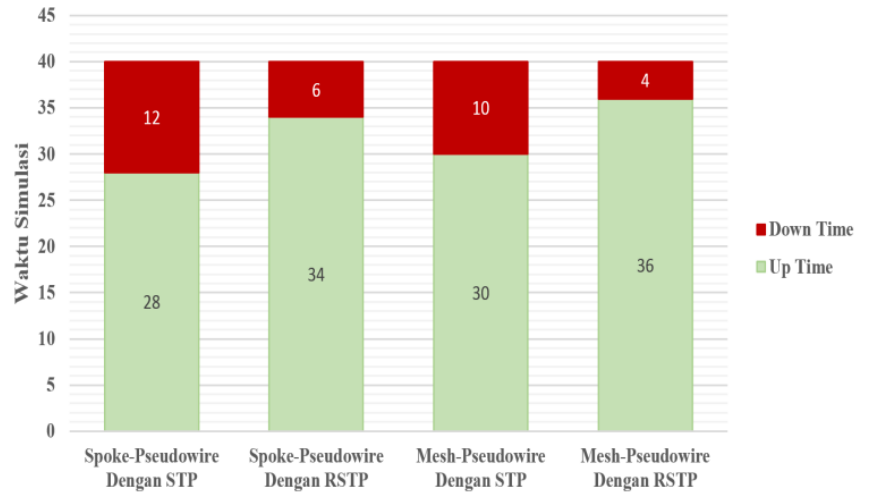

Gambar 9, Grafik Pengamatan Durasi

Down Time Pada Network

Grafik di atas menampilkan durasi down time dan up time pada network ketika network fail, satuan waktunya detik. Berdasarkan hasil ini penerapan VPLS mesh-pseudowire dengan RSTP mengalami durasi down lebih sedikit dibandingkan dengan VPLS spoke-pseudowire RSTP, spokepseudowire STP dan mesh-pseudowire STP. Hal ini di karenakan mekanis me pencegahan loop dengan perbandingan $B P D U$ hanya beroperasi pada akses link VPLS kearah customer. Sedangkan penerapan VPLS spoke-pseudowire dengan STP mengalami down time paling lama yaitu 12 detik dari 40 detik pengamatan. Durasi down time redundant VPLS mesh-pseudowire 6 detik dan spoke-pesudowire 4 detik dengan RSTP merupakan hasil yang paling optimal, hal ini di buktikan dengan availability network yang lebih tinggi di bandingkan dengan STP.

\section{KESIMPULAN DAN SARAN}

Berhubung kebutuhan industry enterprise saat ini semakin men ingkat maka di perlukan IT infrastrutur dengan performa tinggi dan handal, dengan inovasi dari service VPLS melalui MPLS pseudowire L2 ethernet bridging untuk menyediakan koneksi customer yang terpisah secara geografis dan implementasi RSTP pada redundant link di sisi akses maupun backbone dapat memberikan solusi dari kebutuhan tersebut. RSTP digunakan untuk mencegah forwarding loop pada redundant path, sehingga hanya satu link active dalam status forwarding. Dari hasil simulasi VPLS redundant link meshpseudowire dan spoke-pesudowire dengan RSTP membuktikan bahwa performa network terjaga secara end to end karena hanya memakan sedikit down time dibandingkan dengan STP saat mengembalikan ke status forwarding dari discard sehingga data frame yang di kirim antar $C E$ akan terjaga dan tercapainya SLA antara customer dan ISP.

\section{DAFTAR PUSTAKA}

[1] Madhusanka Liyanage, Mika Ylianttila, Andrei Gurtov, “ $A$ Novel Distributed Spanning Tree Protocol for Provider Provisioned VPLS Networks," IEEE ICC, 2014

[2] A. Sajassi, Ed., F. Brockners, D. Mohan, Ed., Y. Serbest, "Virtual Private LAN Service (VPLS) Interoperability 
with Customer Edge (CE) Bridges", IETF RFC 6246, Juni 2011

[3] Guitang Wang, Jun Liu, Liming Wu, Huan Yao, "Three-rings Redundancy Industrial Ethernet based on RSTP”, International Conference on Signal Processing Systems, 2009

[4] K. Kompella, Ed, Y. Rekhter, ed, "Virtual Private LAN Service (VPLS) Using BGP for Auto-Discovery and Signaling", IETF RFC 4761, Januari 2007

[5] M. Lasserre, ed, V.Kompella, ed, "Virtual Private LAN Service (VPLS) Using Label Distribution Protocol (LDP) Signaling", IETF RFC 4762, Januari 2007

[6] R. Gu, J. Dong, M. Chen, Q. Zeng, “Analysis of Virtual Private LAN Service (VPLS) Deployment”, Huawei Technologeis China Telecom, Maret 2011

[7] Zhuo (Frank) Xu, "Designing and Implementing IP/MPLSBased Ethernet Layer 2 VPN Service", Wiley Publishing, Inc., Indianapolis, Indiana, 2010

[8] R. Mohtasin, P.W.C. Prasad, Abeer Alsadoon, G. Zajko, A Elchouemi, Ashutosh Kumar Singh, "Development of a Virtualized Networking Lab using GNS3 and VMware Workstation", IEEE WiSPNET 2016 conference, 2016 
